\title{
Neurodevelopmental and Neuropsychiatric Disorders in Cobalamin C Disease: A Case Report and Review of the Literature
}

Minh G. Nguyen ${ }^{1.2}$, Lauren Tronick ${ }^{3}$, Faraz Modirian ${ }^{4}$, Rebecca Mardach ${ }^{2.5}$, Aaron D. Besterman ${ }^{1.26}$

1 - University of California San Diego School of Medicine, Department of Psychiatry

2 - Rady Children's Hospital, San Diego

3 - University of California San Diego School of Medicine

4 - Rocky Vista University College of Osteopathic Medicine

5 - University of California San Diego School of Medicine, Department of Pediatrics

6 - Rady Children's Institute for Genomic Medicine

a - Corresponding author: abesterman@ health.ucsd.edu

\begin{abstract}
Cobalamin $\mathrm{C}$ disease is the most common complementation class of Cobalamin disorders. Here, we present a case of a 14-year-old male with early-onset cblC disease and autism spectrum disorder (ASD) admitted to our inpatient medical service for behavioral decompensation. We use this case to highlight key aspects of the neurodevelopmental and neuropsychiatric disorders associated with cblC disease. By incorporating a comprehensive review of existing literature, we highlight salient domains of psychological impairment in cblC disease, discuss the full range of neuropsychiatric presentations, and review clinical management implications unique to cblC disease
\end{abstract}




\section{INTRODUCTION}

Cobalamin $(\mathrm{Cbl})$, commonly known as vitamin B12, is a vital water-soluble vitamin essential for the functioning of numerous enzymes in the body. Cobalamin has a critical role in the synthesis of fatty acids, amino acids, neurotransmitters, and DNA/RNA (Calderon-Ospina et al., 2019). Following consumption, Cbl undergoes a series of intrinsic factor-mediated modifications before it is synthesized into its metabolically active forms. Although rare, each step of modification is at risk of inborn error. The location of the error in the pathway dictates the class of intracellular Cbl metabolism disorders (cblC, cblD, cblF, cblJ or cblX) (Heumer et al., 2017).

The most common class of $\mathrm{Cbl}$ disorders is Cobalamin $\mathrm{C}$ (cblC) disease. The disease remains clinically rare, with approximately 400 cases described in literature (Rahmandar et al., 2014). Incidence is estimated to be 1 in 100,000 and prevalence is estimated to be 1 in 60,000 (Cusmano-Ozag et al., 2007; WeisfeldAdams et al., 2013).

cblC is an autosomal recessive disorder that results from pathogenic variants in the methylmalonic aciduria and homocystinuria type C (MMACHC) gene (Wang et al., 2019). Defective MMACHC protein impairs conversion of $\mathrm{Cbl}$ into two of its physiologically active forms, methylcobalamin ( $\mathrm{MeCbl}$ ) and adenosylcobalamin (AdoCbl). Due to the metabolic processes for which $\mathrm{MeCbl}$ and AdoCbl are cofactors, patients with a deficiency of both $\mathrm{MeCbl}$ and AdoCbl have increased methylmalonic acid (MMA) concentrations, increased homocysteine (Hcy) concentrations, and low methionine (MET) levels (Martinelli et al., 2011; Whitaker et al., 2018; Wang et al., 2019).

The pathophysiology of the neuropsychiatric disturbances seen in cblC disease is not fully understood. It is theorized that elevated levels of MMA and $\mathrm{Hcl}$ within the context of low MET levels predispose patients to microangiopathic disease (Sharma et al., 2007). Elevated levels of Hcl is also associated with declining cognitive performance in elderly adults (Kamath et al., 2006) as a result of damage to vascular endothelium and excessive NMDA stimulation (Debray et al., 2008). Elevated levels of MMA in plasma may be associated with developmental delay due to an increase in odd-chain fatty acid assimilation (Seshradi et al., 2006) and the trapping of toxic metabolites within neurons (Morath et al, 2007). Additionally, the high levels of MMA and $\mathrm{Hcl}$ seen in Vitamin B12 deficiency do not account for many symptoms seen in Cblc (Weisfeld-Adams, 2013). While there has not been evidence of a link between MMA and Hcl levels and long-term overall outcome, it has been reported that plasma MET levels correlated with "overall impression" of the patient's condition (Fiscer et al., 2013).

cblC disease has historically been divided into early-onset and late-onset disease depending on whether it was diagnosed before or after the first year of life. While this distinction may become less relevant in the age of widespread newborn screening, there remains a strong genotype-phenotype correlation with regards to age of onset (Lerner-Ellis et al., 2009). Phenotypic differences may be due to the mutational spectrum of MMACHC and the resulting levels of allelic expression (Carrillo-Carrasco et al., 2012). The most common abnormality is the c.271dupA, which causes a frameshift mutation at codon 91 and a premature termination at codon 105 (Morel et al., 2006). This mutation results in highly morbid, earlyonset disease when present in the homozygous form. When c.271dupA is present in a compound heterozygous state, the phenotype depends on the characteristics of the second mutation. For example, individuals with c.271dupA and c.394C $>\mathrm{T}$ tend to present with disease after the first year of life (LernerEllis et al. 2009). However, even in siblings who share pathogenic variants in MMACHC with similarly elevated Hcy and MMA, clinical presentations can differ, suggesting additional genetic or environmental factors at play (Higashimoto et al., 2020).

The early-onset form accounts for $90 \%$ of all reported cases of cblC (Carrillo-Carrasco et al., 2012). Clinical presentation at onset most commonly yields acute multisystem symptomatology, including hypotonia, lethargy, feeding problems, and developmental delay (Fischer et al., 2014). Neurological features may be severe with microcephaly, hydrocephalus, and epilepsy (Martinelli et al., 2011). 
Untreated, early-onset cblC disease may progress to acute metabolic derangement, hemolytic uremic syndrome, encephalopathy, coma, and death (Sloan et al., 2008).

Late-onset disease presents with predominantly neuropsychiatric symptoms, including progressive cognitive decline, regression, behavioral and personality changes, social withdrawal, psychosis, confusion, and dementia (Carrillo-Carrasco and Venditti, 2012). While the variable age of onset and wide spectrum of clinical presentation pose diagnostic challenges, this form has a less severe course and a more favorable outcome when treated (Weisfield-Adams et al., 2010). 
Although it is well-documented in the literature that early- and late- onset disease have somewhat distinct phenotypic presentations, clinical and anecdotal experience suggest that neurobehavioral manifestations are not so clearly delineated. The spectrum of what has been historically described as early- or late- onset disease has been further impacted by the widespread use of newborn screening, although late-onset cases may still be missed. Additionally, some neuropsychiatric conditions have not been commonly associated with cblC disease, including autism spectrum disorder (ASD), attention deficit hyperactivity disorder (ADHD), mood disorders, and anxiety disorders. Here, we present a case of an adolescent male with early-onset cblC disease, ASD, and ADHD admitted to our inpatient medical service for behavioral decompensation. We use this case to highlight key aspects of neurodevelopmental and neuropsychiatric disorders associated with cblC disease. Specifically, we aim to highlight salient domains of psychological impairment in cblC disease, discuss the full range of neuropsychiatric presentations, and review clinical management implications unique to cblC disease.

\section{RESULTS}

\section{Clinical Presentation}

A 14-year-old boy with a history of cblC disease diagnosed on newborn screening, developmental delay with poor fine motor skills and receptive/expressive language disorder, autism spectrum disorder (ASD), attention deficit hyperactivity disorder (ADHD), strabismus, nystagmus, and myopia, presented to the pediatric emergency department (ED) with behavior changes and poor oral intake. He had not consumed food or water for three days.

His mother reported that he had been developing anxiety and depression over the preceding two months, coinciding with the transition to a new school and interpersonal conflicts with a friend. One month prior to presentation, he was taken to his outpatient psychiatrist who initiated sertraline 50mg oral daily; his mood deteriorated further with the onset of acute agitation at school one week prior to admission. He began to refuse food, drink and medication. Patient also began to make suicidal statements and was intercepted twice that week attempting to hurt himself with a screwdriver and then a knife. They revisited their outpatient psychiatrist three days prior to hospitalization who prescribed aripiprazole $5 \mathrm{mg}$ daily, but the patient was nonadherent and continued to exhibit significant agitation and dysphoria.

On evaluation in the ED, the patient was agitated, pacing, and uncooperative, with "aggressive behavior" and "hallucinations/psychosis". No further information was available about his hallucinations on chart review. He was admitted to the general pediatrics service for further management of poor oral intake and dehydration, acute evaluation of his $\mathrm{Cbl}$ status, and behavioral decompensation. Metabolic genetics and psychiatry were both consulted.

On review of the patient's history, he was diagnosed with cblC at two weeks of age on newborn screening. Subsequent genetic testing was not pursued for unknown reasons, but his specific MMACHC variant is not reported. He began treatment with hydroxocobalamin, folinic acid, carnitine and mild protein restriction at one month of age. He was also treated with betaine since six months of age. The patient's family reported consistent adherence with the medication regimen. Notably, at eight months of age, the patient was connected with services for global developmental delay and began receiving speech therapy, occupational therapy, and physical therapy. He began following with ophthalmology at one year of age. He was diagnosed with ASD at five years old and in-home Applied Behavioral Analysis (ABA) therapy was initiated. Home medications at the time of admission included hydroxycobalamin $2 \mathrm{~mL}$ of $1000 \mathrm{mcg} / \mathrm{mL}$ intramuscularly daily, leucovorin $10 \mathrm{mg}$ by mouth daily, 
levocarnitine $4 \mathrm{~mL}$ of $1 \mathrm{GM} / 10 \mathrm{ML}$ orally three times per day, and betaine $1300 \mathrm{mg}$ orally daily. His methionine level eight months prior to hospitalization was $36 \mu \mathrm{mol} / \mathrm{L}(14-48 \mu \mathrm{mol} / \mathrm{L})$. MMA levels were trending upward from $32,720 \mathrm{nmol} / \mathrm{L}$ ten months prior to hospitalization to $46,840 \mathrm{nmol} / \mathrm{L}$ eight months prior. Serum homocysteine level was $85.6 \mathrm{umol} / \mathrm{L}$ ( $<11.4 \mathrm{umol})$ eight months prior to presentation and $35 \mathrm{umol} / \mathrm{L}$ in 2010. Psychiatric medications included aripiprazole $5 \mathrm{mg}$ and sertraline $50 \mathrm{mg}$ daily. He was never been trialed on medications for ADHD, and he had no prior history of a behavioral episode like the one that led to this hospitalization. No neuropsychiatric testing or brain imaging was available.

The ED obtained CBC, CMP, B12 and ammonia levels which were all unremarkable. Venous blood gas was consistent with respiratory rather than metabolic acidosis. Head CT revealed mild diffuse cerebral parenchymal volume loss, indicative of a chronic process with no acute abnormality. The patient had a $5.2 \mathrm{~kg}$ weight loss over the course of four months, placing the patient in the 4 th percentile by weight-for- age.

On hospital day (HD) 1, the patient presented with a flat affect, avoidant eye contact, inappropriate tone, and loud speech. He endorsed feeling "sad" but would not elaborate. When asked about his experience at school, he became agitated and combative. There were reports of hallucinations during this encounter as well but no additional description was available on chart review. Two doses of olanzapine $5 \mathrm{mg}$, one dose of lorazepam $1 \mathrm{mg}$, and soft restraints were required in order to place intravenous lines for fluid resuscitation. The soft restraints were necessary throughout hospitalization, as he repeatedly removed his IV lines without them. His home medications were continued. During the evening, the patient became agitated and combative, requiring olanzapine 10mg and lorazepam 1mg.

At the time of psychiatric consultation on HD 2, the boy was sitting up in bed with soft restraints. He appeared younger than stated age, thin, and short-statured. He was asking about discharge, irritable, reactive, and angry which limited the interview. His speech was dysarthric and loud with dysprosody and simple language. He reluctantly answered one question with "I don't know" and declined to answer any further questions. He was given a preliminary diagnosis of unspecified anxiety and depressive disorders. Oral hydroxyzine $50 \mathrm{mg}$ and IV chlorpromazine $25 \mathrm{mg}$ were prescribed as-needed for agitation.

The patient ate well in the afternoon and did not discuss why he had been refusing food prior. He remained agitated and irritable, pacing around the room with his hands over his ears. He utilized PRN hydroxyzine for anxiety.

The patient was discharged on HD 3 following good oral intake for three meals. Lab values that resulted following discharge revealed serum MMA 23210 (87-318nmol/L), urine MMA 59 (0-5), and Hcy 116.4 (<11.4 umol/L). Copper, zinc and B1 levels were within normal limits.

\section{DISCUSSION}

\section{Neurodevelopmental Disorders}

As exemplified by our patient's neurodevelopmental history, global developmental delay (GDD) is one of the most common features of early-onset cblC (Fischer et al., 2014). It is present in 33-64\% of children with early-onset disease (Rosenblatt et al. 1997; Wang et al., 2019). Similarly, intellectual disability (ID) is present in approximately half of children with early-onset disease (Beauchamp et al., 2009). However, much less is known about the specific domains of developmental impairment, as only a few studies have completed structured neuropsychological and neurodevelopmental assessments of patients with cblC disease (Beauchamp et al., 2009; Tangney et al., 2009; Shinnar and Singer, 1984; Weisfeld-Adams et al., 2013). The most consistently observed domain of impairment is 
executive functioning (Tangney et al., 2009) (see Table 1). This specific deficit was observed in two 12- year-old females with cblC disease (Beauchamp et al., 2009). Consistent with the fine-motor delay in our patient, motor function was most affected while daily living skills and communication were relatively spared. Verbal expression, comprehension, adaptive skills, and social skills seem to be relatively spared.

To our knowledge, there is only one report of a patient with cblC disease and ASD (Sharma et al., 2017). There are several different reasons that this may be. First,ASD may be underdiagnosed and/or underreported in the cblC disease population because of multisystem impairment, such as cooccurrence with IDD (Thurm et al., 2020), compounded by a lack of direct assessment and consistent reporting. Additionally, as genetic testing was not pursued for this patient, there is a possibility of an additional undiagnosed genetic disease associated with ASD. It is also important to consider that the two reported cases of ASD associated with cblC disease may represent random co-occurrence, as ASD is quite common in the general population (Maenner, et al., 2021). However, if there is truly a low rate of ASD in cblC disease, this would suggest that cblC disease uniquely affects regions of the brain involved in cognitive and developmental processes not associated with social skills and communication, which are impaired in ASD. This differs from many other genetic disorders associated with neurodevelopmental disabilities, as patients with such disorders tend to be predisposed to GDD, ID, and ASD (Hanly et al., 2020). How the pathophysiology of cblC disease may predispose individuals to ID and GDD, but not ASD, warrants further exploration.

\section{Psychosis and Other Neuropsychiatric Disorders}

It was unclear if our patient experienced true psychosis, as he was described as exhibiting "hallucinations/psychosis" in the ED and again by the medical team upon admission. Upon psychiatric evaluation, however, the patient did not appear internally preoccupied, paranoid, or otherwise psychotic. He was unwilling to answer questions pertaining to psychotic experiences, so our direct assessment was limited, but his mother denied behaviors consistent with psychosis. However, because psychosis has been associated with cblC disease, we recommended ongoing monitoring.

Psychosis is a relatively uncommon symptom of cblC; while one study reported that only one of 11 patients displayed psychotic features (Ben-Omran et al., 2007; Thauvin-Robinet et al. 2007), only six studies report symptoms of psychosis at all (Higashimoto et al., 2020; Kuo et al., 2008; Rahmander et al., 2014; Roze et al., 2003; Thauvin-Robinet et al., 2007). All previously-documented cases of psychosis in cblC were within the context of late-onset disease. A range of psychotic symptoms have been described in patients with cblC disease, including visual hallucinations, auditory hallucinations, and delusions (Rahmander et al., 2014; Roze et al., 2003; Thauvin-Robinet et al., 2007). Only two reported patients required psychiatric hospitalization for psychosis in the context of cblC disease, suggesting that psychosis may be relatively mild and can usually be managed on an outpatient basis (Rahmander et al., 2014; Roze et al., 2003; Thauvin-Robinet et al., 2007). Psychosis associated with late-onset cblC disease appears to respond well to standard cblC treatment, as every patient had an adequate resolution of symptoms (Higashimoto et al., 2020; Kuo et al., 2008; Rahmander et al., 2014; Roze et al., 2003; Thauvin-Robinet et al., 2007).

While mood symptoms have been noted in patients with cblC disease, discussion remains limited. Our patient was diagnosed with depression two months prior to presentation and treated with an antidepressant. Seven patients with cblC disease and a history of depression have been reported (Collison et al., 2015; Thauvin-Robinet, 2007; Tsai et al., 2007; Wu et al., 2017). Of these cases, two were brothers who presented with mania several months after a depressive episode (Wu et al., 2017). Notably, four of six cases experienced concomitant psychosis with the presenting mood disorder (Thauvin-Robinet, 2007; Tsai et al., 2007; Wu et al., 2017), increasing the suspicion that our patient 
may indeed have experienced hallucinations. Depression may be a more common neuropsychiatric manifestation of cblC than previously thought, and patients with cblC should be screened accordingly (Liu et al., 2014).

The anxiety, depression, and suicidal ideation experienced by our patient during adolescence suggests psychiatric comorbidities can occur regardless of cblC disease age-of-onset. As only two other documented cases of cblC mention associated anxiety, the symptom has not been well-described (Huemer et al., 2014). Previous reports suggest that onset of psychiatric symptoms is most common in adolescence (Huemer et al., 2016), which again mimics the trajectory of psychiatric illness in the general population, making it challenging to distinguish cblC-related symptoms from comorbid psychiatric symptoms.

Our patient was noted to have significant issues with attention and hyperactivity from an early age, officially diagnosed with ADHD at age eight. Although cognitive deficits in attention and executive function have been reported in association with cblC disease, this case is the first to associate a diagnosis of ADHD with cblC disease (Beauchamp et al., 2009; Bellrose et al., 2015; Shinnar and Singer, 1984; Tangney et al., 2009)

\section{When to Consider cblC Disease as a Cause of Neurodevelopmental and Neuropsychiatric Disorders}

Most patients with cblC disease in the United States are currently identified on newborn screening (Whitaker et al., 2018). However, for patients growing up in areas where this newborn screening is not yet standard, or older patients who may not have had screening for cblC disease, symptoms of cblC disease may present for the first time with neurodevelopmental delays in childhood or neuropsychiatric symptoms later in life. Clinicians should be aware of when to suspect cblC disease as an underlying cause of neurodevelopmental and neuropsychiatric symptoms. However, it should be noted that many of these symptoms are not specific to cblC disease, but may be indicative of one of many inborn errors of metabolism, a topic that is beyond the scope of this review, but has been discussed in-depth elsewhere (Huemer et al, 2016, Demily et al., 2014)

Patients presenting with developmental delays, neurologic deficits, psychiatric disturbances, and/or thromboembolic events should be considered for evaluation of late-onset cblC disease (ThauvinRobinet et al., 2007). Generally, metabolic workup is indicated in patients with psychiatric symptoms that are resistant to treatment, wax and wane, or worsen (Huemer et al, 2016). Other atypical symptoms include early- or acute-onset, catatonia, confusion, and cognitive change (Demily et al., 2014). Rarely, mental disturbances manifest prior to neurologic symptoms (Marks and Zukerberg, 2004), so consideration of cblC disease in patients with psychiatric symptoms that fit this intermittent pattern is warranted. Visual disturbances such as nystagmus, retinopathy, and decreased visual acuity and various hematological changes (including thrombocytopenia, megaloblastic marrow, leukopenia, neutropenia) have also been noted. If these symptoms are present in the context of progressive neurologic abnormalities, cblC disease must remain on the differential (Rosenblatt et al., 1997).

On MRI, cerebral and spinal cord atrophy are morphological hallmarks of Cbl-related disorders (Huemer et al., 2018). More specifically, bilateral symmetric patchy lesions in deep white matter were most commonly seen (Gurkas et al., 2015). White matter disease can progress from isolated periventricular or periatrial hyperintensities, coalesce into larger lesions, and eventually lead to diffuse white matter loss (Rossi et al., 2001). Cerebellar lesions and atrophy and basal ganglia lesions have also been described (Wang et al. 2019). Other abnormal MRI findings include callosal thinning, a craniocaudally short pons, an increased signal in periatrial white matter (Weisfeld-Adams et al., 2013) and leukoencephalopathy with corpus callosum agenesis (Thauvin-Robinet et al., 2007). A MRI was not obtained for this patient during his admission however would have provided useful information. 


\section{Management Considerations in Neurodevelopmental and Neuropsychiatric Disorders Associated with cblC Disease}

When clinicians consider management strategies for cblC, they must consider a bimodal approach: Treating the underlying metabolic disturbance and/or treating the neurodevelopmental or neuropsychiatric disorder symptomatically. In neuropsychiatry, we strive to treat the underlying cause of any condition. In most cases, the underlying cause is unknown and thus patients can only be treated symptomatically. cblC disease is a rare example of a known cause of neuropsychiatric disturbance and thus first targeting metabolic disturbance is recommended. There are reports of improved neuropsychiatric symptoms upon metabolic normalization (Augoustides-Savvopoulou et al., 1999; Boxer et al., 2005; Roze et al., 2003; Shinnar and Singer, 1984; Kuo et al., 2008). For example, one study described improved symptoms in all cblC patients with psychiatric disturbance after two-to-four weeks of personalized treatment, which included cyanocobalamin and/or hydroxocobalamin, betaine, folic acid, L-carnitine and compound vitamin B (Wang et al., 2019). In the case of our patient, the only metabolic treatment he received during hospitalization was continuation of home medications. $\mathrm{He}$ eventually stabilized enough psychiatrically for discharge. As MMA levels upon discharge had improved, it is possible that adherence to cblC treatment contributed to normalization of metabolic derangements and thus improvement of behavioral status.

Neuropsychiatric symptoms in late-onset disease are particularly responsive to metabolic treatment (Augoustides- Savvopoulou et al., 1999; Boxer et al., 2005; Roze et al., 2003; Shinnar and Singer, 1984), while early- onset disease often progresses despite early diagnosis and intervention (Beauchamp et al., 2009; Biancheri et al., 2001; Fischer et al., 2014). Specifically, symptoms of psychosis, anxiety, depression, mood lability, impulsivity, and aggression also may respond well to treatment in late-onset disease (Huemer et al. 2017; Kuo et al., 2008). Executive function seems to improve with treatment, with two studies showing attention, concentration and memory having improved most markedly (Boxer et al., 2005; Huemer et al., 2016; Kuo et al., 2008; Shinnar and Singer, 1984). Similarly, patients with more prominent neurologic symptoms may respond well to metabolic treatment as well. For example, a reported 10-year-old female with recent onset of learning difficulties, behavioral changes, ataxia, myoclonic jerks, and progressive dementia who experienced full recovery with a normal neurologic exam following treatment (Augoustides-Savvopoulou, 1999).

However, a direct relationship between biochemical levels and neuropsychiatric outcomes is not wellestablished, as improvement of metabolic parameters does not correlate with clinical presentation, nor does it protect against severe, long-term complications (Weisfeld-Adams et al., 2013; Whitaker et al., 2018). A complete resolution of neuropsychiatric symptoms upon metabolic normalization should not always be expected, regardless of age of onset, as neuropsychiatric disease is inevitably multifactorial. It is also important to consider the role of external factors in any psychiatric crisis, which can have a synergistic effect with metabolic derangement. In our case for example, the distress that our patient experienced in the setting of a new school and interpersonal conflict may have resulted in poor oral intake, medication nonadherence and subsequent exacerbation of metabolic derangement. Thus, the emergence of neuropsychiatric disease in our case may not necessarily represent metabolic derangement or disease progression, but rather the complex interaction of psychosocial factors with the natural course of cblC disease.

The psychotropic management of psychiatric and behavioral symptoms in patients with cblC disease has not been well studied. Aripiprazole, risperidone, valproate and escitalopram have each been used to treat neuropsychiatric symptoms in individual patients with cblC disease, but they were not particularly effective in reducing symptoms, which may suggest some degree of treatment-resistance, although this is not well-established (Kuo et al., 2008; Wu et al., 2017). For now, psychiatric 
management should be based on current best-practice guidelines for each neuropsychiatric symptom or disorder, as there are no contraindications to specific psychotropic medications in cblC disease. One study reported that olanzapine increases levels of serum cobalamin, however it is not clear that olanzapine should be avoided based on these very preliminary results (Hasnat et al., 2018). In our case, the patient was given multiple, as-needed doses of olanzapine and lorazepam. This may have also contributed to his psychiatric stabilization that was satisfactory for discharge.

Given the rapid recent development of gene-modifying therapies, there is significant hope that many neurogenetic conditions, including cblC disease, may soon have significantly improved treatments and outcomes (Poletti and Biffi, 2019). However, additional research is still warranted on the characterization of psychiatric symptoms seen in cblC. Such research would provide better guidance as to when cblC should be considered as the underlying cause of neuropsychiatric illness and will inform endpoint selection for future clinical trials. Furthermore, more data is required to distinguish whether psychiatric disorders such as depression, anxiety and psychosis are related to cblC or merely co-occurring psychiatric illnesses. This distinction may have treatment implications and necessitates further exploration, as cblC-related psychiatric symptoms may uniquely respond to metabolic correction as opposed to psychiatric illness that is purely co-occurring.

\section{METHODS}

\section{Consent and Enrollment}

Parental consent was obtained for this study through Rady Children's Hospital, San Diego.

\section{Literature Review}

We completed a review of the literature to produce a comprehensive list of studies describing neurodevelopmental and neuropsychiatric aspects of cblC disease. Search terms included "cobalamin C disease" and "neurodevelopment," "psychiatric," "autism," "psychosis," and "dementia," in both PubMed and Google Scholar. We reviewed the results for reported cases of individuals with cblC disease with neurodevelopmental and neuropsychiatric symptoms, paying particular attention to studies that reported specific neurobehavioral assessment measures. References and citing studies were reviewed for additional published cases. Notably, the term, "dementia" has been retained in the DSM-V for continuity, however the term, "neurocognitive disorder" is more widely used; we reflected this semantic combination in our synthesis of the literature.

\section{ADDITIONAL INFORMATION}

\section{Ethics Statement}

Written consent for publication of clinical details was obtained via a Rady Children's Hospital San Diego (RCHSD) release form, reviewed by the RCHSD Privacy Board, in accordance with RCHSD rules for case reports.

\section{Funding}

Funding for this study was provided by Rady Children's Institute for Genomic Medicine.

\section{Competing Interest Statement}


The authors have declared no competing interest.

\section{Acknowledgements}

The authors thank the family for participation in the study.

\section{REFERENCES}

Augoustides-Savvopoulou, P., Mylonas, I., Sewell, A. C., \& Rosenblatt, D. S. (1999). Reversible dementia in an adolescent with cblC disease: clinical heterogeneity within the same family. Journal of inherited metabolic disease, 22(6), 756-758. https://doi.org/10.1023/a:1005508620919

Arnold, M., Sloan, J. L., Achilly, N. P., Elliot, G., Onojafe, I. F., Brooks, B. P., \& Venditti, C. P. (2016).

46. The First Viable Mouse Model of cblC Type Combined Methylmalonic Acidemia and Homocysteinemia: AAV Gene Therapy Rescues Neonatal Lethality and Provides Insight into Disease- Associated Retinal Degeneration. Molecular Therapy, 24, S20-S21.

Al-Farsi YM, Waly MI, Deth RC, et al. Low folate and vitamin B12 nourishment is common in Omani children with newly diagnosed autism. Nutrition. 2013;29(3):537-541. https://doi.org/10.1016/j.

Nut.2012.09.014.

Beauchamp, M. H., Anderson, V., \& Boneh, A. (2009). Cognitive and social profiles in two patients with cobalamin C disease. Journal of Inherited Metabolic Disease, 32(S1), 327-334. https://doi.org/10.1007/s10545-009-1284-8

Ben-Omran, T. I., Wong, H., Blaser, S., \& Feigenbaum, A. (2007). Late-onset cobalamin-C disorder: A challenging diagnosis. American Journal of Medical Genetics Part A, 143A(9), 979-984. https://doi.org/10.1002/ajmg.a.31671

Biancheri R, Cerone R, Rossi A et al (2002) Early-onset cobalamin C/D deficiency: epilepsy and electroencephalographic features. Epilepsia 43:616-622

Boxer, A. L., Kramer, J. H., Johnston, K., Goldman, J., Finley, R., \& Miller, B. L. (2005). Executive dysfunction in hyperhomocystinemia responds to homocysteine-lowering treatment. Neurology, 64(8), 1431-1434. https://doi.org/10.1212/01.WNL.0000158476.74580.A8

Calderón $\square$ Ospina, C. A., \& Nava $\square$ Mesa, M. O. (2019). B Vitamins in the nervous system: Current knowledge of the biochemical modes of action and synergies of thiamine, pyridoxine, and cobalamin. CNS Neuroscience \& Therapeutics, 26(1), 5-13. https://doi.org/10.1111/cns.13207

Carrillo-Carrasco, N., \& Venditti, C. P. (2012). Combined methylmalonic acidemia and homocystinuria, cblC type. II. Complications, pathophysiology, and outcomes. Journal of inherited metabolic disease, 35(1), 103-114. https://doi.org/10.1007/s10545-011-9365-x

Carrillo-Carrasco, N., Chandler, R. J., \& Venditti, C. P. (2012). Combined methylmalonic acidemia and homocystinuria, cblC type. I. Clinical presentations, diagnosis and management. Journal of inherited metabolic disease, 35(1), 91-102. https://doi.org/10.1007/s10545-011-9364-y

Chang, K.-J., Zhao, Z., Shen, H.-R., Bing, Q., Li, N., Guo, X., \& Hu, J. (2020). Adolescent/adult- 
onset homocysteine remethylation disorders characterized by gait disturbance with/without psychiatric symptoms and cognitive decline: a series of seven cases. Neurological Sciences, 42(5), 1987-1993. https://doi.org/10.1007/s 10072-020-04756-0

Chern, T., Achilleos, A., Tong, X., Hsu, C.-W., Wong, L., \& Poché, R. A. (2020). Mouse models to study the pathophysiology of combined methylmalonic acidemia and homocystinuria, cblC type. Developmental Biology, 468(1-2), 1-13. https://doi.org/10.1016/j.ydbio.2020.09.005

Collison, F. T., Xie, Y. (Angela), Gambin, T., Jhangiani, S., Muzny, D., Gibbs, R., Lupski, J. R., Fishman, G. A., \& Allikmets, R. (2015). Whole Exome Sequencing Identifies an Adult-Onset Case of Methylmalonic Aciduria and Homocystinuria Type C (cblC) with Non-Syndromic Bull's Eye Maculopathy. Ophthalmic Genetics, 36(3), 270-275. https://doi.org/10.3109/13816810.2015.1010736

Cusmano-Ozog K, Levine S, Martin M, Nicholas E, Packman S, Rosenblatt D, Cederbaum S, Cowan T, Enns G (2007). Program for SIMD Annual Meeting. Molecular Genetics and Metabolism, 90, 227-265.

Debray, F. G., Boulanger, Y., Khiat, A., Decarie, J. C., Orquin, J., Roy, M. S., Lortie, A., Ramos, F., Verhoeven, N. M., Struys, E., Blom, H. J., Jakobs, C., Levy, E., Mitchell, G. A., \& Lambert, M. (2008). Reduced brain choline in homocystinuria due to remethylation defects. Neurology, 71(1), 44-49. https://doi.org/10.1212/01.wnl.0000316391.40236.c3

Demily, C., \& Sedel, F. (2014b). Psychiatric manifestations of treatable hereditary metabolic disorders in adults. Annals of General Psychiatry, 13(1). https://doi.org/10.1186/s12991-014-0027-x

Enns, G. M., Kinsman, S. L., Perlman, S. L., Spicer, K. M., Abdenur, J. E., Cohen, B. H., Amagata, A., Barnes, A., Kheifets, V., Shrader, W. D., Thoolen, M., Blankenberg, F., \& Miller, G. (2012). Initial experience in the treatment of inherited mitochondrial disease with EPI-743. Molecular genetics and metabolism, 105(1), 91-102. https://doi.org/10.1016/j.ymgme.2011.10.009

Fischer, S., Huemer, M., Baumgartner, M., Deodato, F., Ballhausen, D., Boneh, A., Burlina, A. B., Cerone, R., Garcia, P., Gökçay, G., Grünewald, S., Häberle, J., Jaeken, J., Ketteridge, D., Lindner, M., Mandel, H., Martinelli, D., Martins, E. G., Schwab, K. O., Gruenert, S. C., ... Dionisi-Vici, C. (2014). Clinical presentation and outcome in a series of 88 patients with the cblC defect. Journal of inherited metabolic disease, 37(5), 831-840. https://doi.org/10.1007/s10545-014-9687-6

Gurkas, E., Karalok, Z. S., Taskin, B. D., Aydogmus, U., Yilmaz, C., Arhan, E., \& Kabacam, G. B. (2015). PP15.11 - 3031: Brain magnetic resonance imaging findings in children with recurrent headache. European Journal of Paediatric Neurology, 19, S92. https://doi.org/10.1016/s10903798(15)30308-1

Hanly, C., Shah, H., Au, P., \& Murias, K. (2021). Description of neurodevelopmental phenotypes associated with 10 genetic neurodevelopmental disorders: A scoping review. Clinical genetics, 99(3), 335-346. https://doi.org/10.1111/cge.13882

Hasnat, F., Dewan, Z. F., Misbahuddin, M., Akhter, N., Shamsunnahar, J., \& Bhuiyan, H. A. (2018). Folic acid, vitamin B12 and homocysteine levels following olanzapine administration in schizophrenia patients. Bangabandhu Sheikh Mujib Medical University Journal, 11(1), 11-16.

Higashimoto, T., Kim, A. Y., Ogawa, J. T., Sloan, J. L., Almuqbil, M. A., Carlson, J. M., Manoli, I., 
Venditti, C. P., Gunay-Aygun, M., \& Wang, T. (2019). High-dose hydroxocobalamin achieves biochemical correction and improvement of neuropsychiatric deficits in adults with late onset cobalamin C deficiency. JIMD reports, 51(1), 17-24. https://doi.org/10.1002/jmd2.12087

Huemer, M., Scholl-Bürgi, S., Hadaya, K., Kern, I., Beer, R., Seppi, K., Fowler, B., Baumgartner, M. R., \& Karall, D. (2014). Three new cases of late-onset cblC defect and review of the literature illustrating when to consider inborn errors of metabolism beyond infancy. Orphanet Journal of Rare Diseases, 9(1). https://doi.org/10.1186/s13023-014-0161-1

Huemer, M., Diodato, D., Schwahn, B., Schiff, M., Bandeira, A., Benoist, J.-F., Burlina, A., Cerone, R., Couce, M. L., Garcia-Cazorla, A., la Marca, G., Pasquini, E., Vilarinho, L., Weisfeld-Adams, J. D., Kožich, V., Blom, H., Baumgartner, M. R., \& Dionisi-Vici, C. (2016). Guidelines for diagnosis and management of the cobalamin-related remethylation disorders cblC, cblD, cblE, cblF, cblG, cblJ and MTHFR deficiency. Journal of Inherited Metabolic Disease, 40(1), 21-48. https://doi.org/10.1007/s10545-016-9991-4

Huemer, M., Diodato, D., Martinelli, D., Olivieri, G., Blom, H., Gleich, F., Kölker, S., Kožich, V., Morris, A. A., Seifert, B., Froese, D. S., Baumgartner, M. R., Dionisi-Vici, C., Alcalde Martin, C., Baethmann, M., Ballhausen, D., Blasco-Alonso, J., Boy, N., Bueno, M., \& Burgos Peláez, R. (2018). Phenotype, treatment practice and outcome in the cobalamin-dependent remethylation disorders and MTHFR deficiency: data from the E-HOD registry. Journal of Inherited Metabolic Disease. https://doi.org/10.1007/s10545-018-0238-4

Kamath, A. F., Chauhan, A. K., Kisucka, J., Dole, V. S., Loscalzo, J., Handy, D. E., \& Wagner, D. D. (2006). Elevated levels of homocysteine compromise blood-brain barrier integrity in mice. Blood, 107(2), 591-593. https://doi.org/10.1182/blood-2005-06-2506

Lerner-Ellis, J. P., Anastasio, N., Liu, J., Coelho, D., Suormala, T., Stucki, M., Loewy, A. D., Gurd, S., Grundberg, E., Morel, C. F., Watkins, D., Baumgartner, M. R., Pastinen, T., Rosenblatt, D. S., \& Fowler, B. (2009). Spectrum of mutations in MMACHC, allelic expression, and evidence for genotypephenotype correlations. Human mutation, 30(7), 1072-1081. https://doi.org/10.1002/humu.21001

Liu, Y., Ji, Y., Wang, Y., Zhang, B., Fang, G., Wang, J., Sun, G., \& Lu, H. (2014). Clinical analysis of late-onset methylmalonic acidaemia and homocystinuria, cblC type with a neuropsychiatric presentation. Journal of Neurology, Neurosurgery \& Psychiatry, 86(4), 472-475.

https://doi.org/10.1136/jnnp-2014- 308203

Maenner MJ, Shaw KA, Baio J, et al. Prevalence of autism spectrum disorder among children aged 8 years-Autism and Developmental Disabilities Monitoring Network, 11 sites, United States, 2016. MMWR Surveill Summ 2020;69(No. SS-4). 10.15585/mmwr.ss6904a1

Marks, P. W., \& Zukerberg, L. R. (2004). Case records of the Massachusetts General Hospital. Weekly clinicopathological exercises. Case 30-2004. A 37-year-old woman with paresthesias of the arms and legs. The New England journal of medicine, 351(13), 1333-1341 https://doi.org/10.1056/NEJMcpc040921

Martinelli, D., Deodato, F., \& Dionisi-Vici, C. (2011). Cobalamin C defect: natural history, pathophysiology, and treatment. Journal of inherited metabolic disease, 34(1), 127-135. https://doi.org/10.1007/s10545-010-9161-z 
Morel, C. F., Lerner-Ellis, J. P., \& Rosenblatt, D. S. (2006). Combined methylmalonic aciduria and homocystinuria (cblC): phenotype-genotype correlations and ethnic-specific observations. Molecular genetics and metabolism, 88(4), 315-321. https://doi.org/10.1016/j.ymgme.2006.04.001

Morath, M. A., Okun, J. G., Müller, I. B., Sauer, S. W., Hörster, F., Hoffmann, G. F., \& Kölker, S. (2007). Neurodegeneration and chronic renal failure in methylmalonic aciduria-A pathophysiological approach. Journal of Inherited Metabolic Disease, 31(1), 35-43. https://doi.org/10.1007/s10545-007$0571-5$

National Library of Medicine (U.S.). (January 2013 - February 2017). EPI-743 in Cobalamin C Defect: Effects on Visual and Neurological Impairment. Identifier NCT01793090. https://clinicaltrials.gov/ct2/show/NCT01793090.

Poletti, V., \& Biffi, A. (2019). Gene-Based Approaches to Inherited Neurometabolic Diseases. Human gene therapy, 30(10), 1222-1235. https://doi.org/10.1089/hum.2019.190

Rosenblatt, D. S., Aspler, A. L., Shevell, M. I., Pletcher, B. A., Fenton, W. A., \& Seashore, M. R. (1997). Clinical heterogeneity and prognosis in combined methylmalonic aciduria and homocystinuria (cblC).

Journal of inherited metabolic disease, 20(4), 528-538. https://doi.org/10.1023/a:1005353530303

Rossi, A., Cerone, R., Biancheri, R., Gatti, R., Schiaffino, M. C., Fonda, C., Zammarchi, E., \& Tortori- Donati, P. (2001). Early-onset combined methylmalonic aciduria and homocystinuria: neuroradiologic findings. AJNR. American journal of neuroradiology, 22(3), 554-563.

Roze, E., Gervais, D., Demeret, S., Ogier de Baulny, H., Zittoun, J., Benoist, J. F., Said, G., PierrotDeseilligny, C., \& Bolgert, F. (2003). Neuropsychiatric disturbances in presumed late-onset cobalamin C disease. Archives of neurology, 60(10), 1457-1462. https://doi.org/10.1001/archneur.60.10.1457

Seshadri, S. (2006). Elevated plasma homocysteine levels: Risk factor or risk marker for the development of dementia and Alzheimer's disease? Journal of Alzheimer's Disease, 9(4), 393-398. https://doi.org/10.3233/jad-2006-9404

Sharma, A. P., Greenberg, C. R., Prasad, A. N., \& Prasad, C. (2007). Hemolytic uremic syndrome (HUS) secondary to cobalamin C (cblC) disorder. Pediatric nephrology (Berlin, Germany), 22(12), 2097-2103. https://doi.org/10.1007/s00467-007-0604-1

Shinnar, S., \& Singer, H. S. (1984). Cobalamin C mutation (methylmalonic aciduria and homocystinuria) in adolescence. A treatable cause of dementia and myelopathy. The New England journal of medicine, 311(7), 451-454. https://doi.org/10.1056/NEJM198408163110707

Sloan, J. L., Carrillo, N., Adams, D., \& Venditti, C. P. (2008). Disorders of Intracellular Cobalamin Metabolism. In M. P. Adam (Eds.) et. al., GeneReviews®. University of Washington, Seattle.

Tangney, C. C., Tang, Y., Evans, D. A., \& Morris, M. C. (2009). Biochemical indicators of vitamin B12 and folate insufficiency and cognitive decline. Neurology, 72(4), 361-367.

https://doi.org/10.1212/01.wnl.0000341272.48617.b0 
Thurm, A., Farmer, C., Salzman, E., Lord, C., \& Bishop, S. (2019). State of the Field: Differentiating Intellectual Disability From Autism Spectrum Disorder. Frontiers in psychiatry, 10, 526. https://doi.org/10.3389/fpsyt.2019.00526

Tsai, A. C., Morel, C. F., Scharer, G., Yang, M., Lerner-Ellis, J. P., Rosenblatt, D. S., \& Thomas, J. A. (2007). Late-onset combined homocystinuria and methylmalonic aciduria (cblC) and neuropsychiatric disturbance. American journal of medical genetics. Part A, 143A(20), 2430-2434. https://doi.org/10.1002/ajmg.a.3193

Thauvin-Robinet, C., Roze, E., Couvreur, G., Horellou, M. H., Sedel, F., Grabli, D., Bruneteau, G., Tonneti, C., Masurel-Paulet, A., Perennou, D., Moreau, T., Giroud, M., de Baulny, H. O., Giraudier, S., \& Faivre, L. (2008). The adolescent and adult form of cobalamin C disease: clinical and molecular spectrum. Journal of neurology, neurosurgery, and psychiatry, 79(6), 725-728. https://doi.org/10.1136/jnnp.2007.133025

Wang, S., Yan, C., Wen, B., \& Zhao, Y. (2019). Clinical feature and outcome of late-onset cobalamin $\mathrm{C}$ disease patients with neuropsychiatric presentations: a Chinese case series. Neuropsychiatric Disease and Treatment, Volume 15, 549-555. https://doi.org/10.2147/ndt.s196924

Weisfeld-Adams, J. D., Bender, H. A., Miley-Åkerstedt, A., Frempong, T., Schrager, N. L., Patel, K., Naidich, T. P., Stein, V., Spat, J., Towns, S., Wasserstein, M. P., Peter, I., Frank, Y., \& Diaz, G. A. (2013). Neurologic and neurodevelopmental phenotypes in young children with early-treated combined methylmalonic acidemia and homocystinuria, cobalamin $\mathrm{C}$ type. Molecular genetics and metabolism, 110(3), 241-247. https://doi.org/10.1016/j.ymgme.2013.07.018

Whitaker, A. M., Thomas, N. H., Krivitzky, L. S., \& Ficicioglu, C. H. (2018). Neuropsychological implications of Cobalamin $\mathrm{C}(\mathrm{CblC})$ disease in Hispanic children detected through newborn screening. Applied neuropsychology. Child, 7(2), 143-149.

https://doi.org/10.1080/21622965.2016.1270211

Wu, L.-Y., An, H., Liu, J., Li, J.-Y., Han, Y., Zhou, A.-H., Wang, F., \& Jia, J.-P. (2017). Manicdepressive Psychosis as the Initial Symptom in Adult Siblings with Late-onset Combined Methylmalonic Aciduria and Homocystinemia, Cobalamin C Type. Chinese Medical Journal, 130(4), 492-494. https://doi.org/10.4103/0366-6999.199826

Table 1: Neurodevelopmental Domains of Impairment in cblC Disease

\begin{tabular}{|c|c|c|c|c|c|c|c|}
\hline Source & Attention & $\begin{array}{l}\text { Motor } \\
\text { Skills }\end{array}$ & $\begin{array}{l}\text { Executive } \\
\text { Functioning }\end{array}$ & Communication & $\begin{array}{l}\text { Adaptive } \\
\text { Functioning }\end{array}$ & $\begin{array}{l}\text { Social } \\
\text { functioning }\end{array}$ & Memory \\
\hline $\begin{array}{l}\text { Weisfeld Adams } \\
\text { et al. } 2013\end{array}$ & - & +++ & - & + & + & - & - \\
\hline $\begin{array}{l}\text { Shinnar and } \\
\text { Singer, } 1984\end{array}$ & +++ & - & - & ++ & - & - & +++ \\
\hline $\begin{array}{l}\text { Tangney et al., } \\
2009\end{array}$ & - & - & ++ & - & - & - & - \\
\hline Beauchamp et & +++ & - & - & + & + & + & - \\
\hline
\end{tabular}




\begin{tabular}{|l|l|l|l|l|l|l|l|}
\hline al., 2009 & & & & & & & \\
\hline $\begin{array}{l}\text { Bellrose et al., } \\
2015\end{array}$ & ++ & - & - & - & - & - & - \\
\hline
\end{tabular}

- = not reported; + = mild impairment; ++ = moderate impairment; +++ = severe impairment 


\section{COLD SPRING HARBOR Molecular Case Studies}

\section{Neurodevelopmental and Neuropsychiatric Disorders in Cobalamin C Disease: A Case Report and Review of the Literature}

Minh G Nguyen, Lauren Tronick, Faraz Modirian, et al.

Cold Spring Harb Mol Case Stud published online February 1, 2022

Access the most recent version at doi: $10.1101 / \mathrm{mcs}$.a006179

Published online February 1, 2022 in advance of the full issue.

Accepted Peer-reviewed and accepted for publication but not copyedited or typeset; accepted Manuscript manuscript is likely to differ from the final, published version. Published onlineFebruary 1, 2022in advance of the full issue.

Creative This article is distributed under the terms of the

Commons http://creativecommons.org/licenses/by-nc/4.0/, which permits reuse and

License redistribution, except for commercial purposes, provided that the original author and source are credited.

Email Alerting Receive free email alerts when new articles cite this article - sign up in the box at the Service top right corner of the article or click here. 